\title{
Announcement from AE Editorial Office
}

As the authors' request, the following paper published in Vol.1, No.2, 29-37, 2013 has been withdrawn from the website.

Title: Characterization of insect-fauna of the free-ranging urban dog, Canis domesticus (L.) carcass in tropical region of Pakistan: A tool for forensic entomology

Authors: Farzana Perveen, Anzela Khan

Advances in Entomology Editorial Office

March 34, 2014. 
$24^{\text {th }}$ March, 2013

Dear Editor

I have decided to withdraw the paper title given below:

Characterization of insect-fauna of the free-ranging urban dog, Canis domesticus (L.) carcass in tropical region of Pakistan: A tool for forensic entomology from the journal: Advances in Entomology Vol.1, No.2, 29-37 (2013)

As I am not comfortable to disclose the reason.

I am sorry for the inconvenience caused.

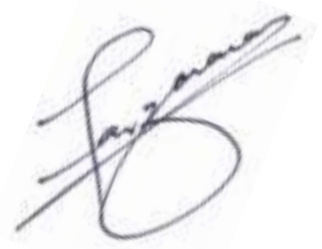

Dr Farzana Perveen

Founder Chairperson \& Associate Professor

Department of Zoology

Controller of Examinations

Shaheed Benazir Bhutto University (SBBU), Main Campus Sheringal, Khyber

Pakhtunkhwa, Pakistan 